\title{
ANALYSIS AND IDENTIFICATION OF POLYPHENOLIC COMPOUNDS IN GREEN FOODS USING A COMBINATION OF HPLC-ESI-IT-TOF-MS/MS
}

\author{
PAVEL ŠKVÁRA *1, Júlia KEZMANOVÁ ${ }^{1}$, CSILLA MIŠL'ANOVÁ ${ }^{1}$, AND ANDREA VoJS StAŇOVÁ ${ }^{1}$ \\ ${ }^{1}$ Department of Analytical Chemistry, Faculty of Natural Sciences, Comenius University, Ilkovičova 6, \\ Bratislava, SK-842 15, SLOVAKIA
}

\begin{abstract}
The beneficial effects of green foods on human health are well known. These benefits are mainly due to polyphenol content. The aim of this work was the development and utilization of an advanced mass spectrometry (MS) technique combined with high-performance liquid chromatography (HPLC) for the analysis and identification of polyphenolic compounds in green foods. HPLC-ESI-MS/MS analyses of selected extracts prepared from various types of green food (Urtica dioica $L$. and Allium ursinum L.) and their polyphenolic profiles were performed by an LCMS-IT-TOF analyzer equipped with electrospray ionization. HPLC separation was conducted by a Kinetex XB-C18 column $(100 \times 2.1 \mathrm{~mm} ; 2.6 \mu \mathrm{m})$ using gradient elution (water $+0.1 \%$ formic acid: acetonitrile $+0.1 \%$ formic acid) with a flow rate of $0.2 \mathrm{~mL} / \mathrm{min}$. The MS1-MS3 analyses were performed within a 50-1000 $\mathrm{m} / \mathrm{z}$ range in both positive and negative ionization modes. The total analysis time was 20 minutes and injected volumes were $2 \mu \mathrm{L}$ and $5 \mu \mathrm{L}$, respectively.
\end{abstract}

Keywords: polyphenolic compounds, green food, HPLC-MS analysis, identification

\section{Introduction}

From a chemical point of view, antioxidants are phenolic compounds derived from simple phenols up to complex polyphenols. An antioxidant is a substance whose molecules limit the activity of oxygenated compounds, namely reduce their likelihood or convert them into a less reactive state. Antioxidants limit the oxidation process in the body or in the mixtures in which they are found. In food, they extend their expiration date. In the body, they reduce the likelihood of certain types of diseases [1].

The main reason for monitoring the presence and activity of antioxidants is their beneficial effect on the human organism. Their health benefits include antioxidant, antibacterial, anticarcinogenic, anti-allergenic and anti-inflammatory properties [2-4]. Antioxidants in green foods belong to a group of low-molecular-weight natural antioxidants whose scientific name is phenolic compounds [5]. Green foods are characterized into four basic groups: herbs and spices, fruits, vegetables and nuts.

Despite the fact that numerous polyphenolic compounds have been detected in green food, there is still a need for new reliable analytical methods. The most common procedures for the identification and determination of polyphenolic compounds in green food are based on sample pretreatment by liquid-liquid extraction followed by separation and identification using high-performance liquid chromatography coupled with tandem mass spec-

\footnotetext{
*Correspondence: skvara1@uniba.sk
}

trometry (HPLC-MS/MS) [6]. Several authors are concerned with the identification and characterization of phenolic compounds in green foods using a combination of high-performance liquid chromatography and mass spectrometry with electrospray ionization (HPLC-ESI-MS) and atmospheric pressure chemical ionization (HPLCAPCI-MS). For example, HPLC-ESI-MS was used to separate and identify phenolic acids in custard apples [7], tannins in chestnut samples [8], phenolic compounds in groundnuts [9], tomatoes [10], spinach [11], and gingerol-related species (gingerols and shogaols) in ginger [12]. The HPLC-APCI-MS/MS method was used to identify carotenoids in samples of mango and citruses [13]. The HPLC-ESI-MS method was also used to analyze samples of nettles [14] and bear's garlic [15].

The aim of this work was to analyze and identify polyphenolic compounds in selected samples of green food using a combination of high-performance liquid chromatography and high-resolution mass spectrometry techniques.

\section{Experimental}

\subsection{Instrumentation}

All HPLC-ESI-MS/MS analyses were performed by using a Shimadzu LCMS-IT-TOF ${ }^{\mathrm{TM}}$ mass spectrometer (Shimadzu, Kyoto, Japan). This mass spectrometer combines an electrospray ionization (ESI), a 3D quadrupole ion trap (IT) and an orthogonal acceleration time-of-flight 
analyzer (TOF) to provide both a high degree of sensitivity and resolution of ions. The HPLC part consisted of an autosampler (SIL-20A), high pressure pumps (LC20AD), a thermostat (CTO-20A), a diode array detector (SPD-M20A), a degasser together with a mixing system (DGU-20A5) and system controller (CBM-20A). LCMS Solutions v. 3.5.1 (Shimadzu) software was used for data acquisition and evaluation.

Chromatographic separation of the polyphenolic compounds was performed on a Kinetex XB-C18 column $(100 \times 2.1 \mathrm{~mm} ; 2.6 \mu \mathrm{m})($ Phenomenex, Torrance, CA, USA). Acidified water and acetonitrile (both with an addition of $0.1 \%$ or $10 \mathrm{mmol} / \mathrm{L}$ of formic acid) were used as mobile phases. Gradient elution of the mobile phase was used. The flow rate of the mobile phase was $0.2 \mathrm{~mL} / \mathrm{min}$. The gradient program was $0 \mathrm{~min} .: 5 \% \mathrm{~B} ; 3 \mathrm{~min} .: 10 \%$ B; 8 min.: $40 \%$ B; 10 min.: $60 \%$ B; 11 min.: $90 \%$ B; 12 min.: $90 \%$ B; 12.1 min.: $5 \% \mathrm{~B}$; and 20 min.: $5 \%$ B. The chromatographic column was thermostated at $40{ }^{\circ} \mathrm{C}$. All MS analyses were performed in both positive and negative ionization modes. The voltages at the ESI capillaries were $+4.5 \mathrm{kV}$ and $-3.5 \mathrm{kV}$. The range of recorded values was set at $50-1000 \mathrm{~m} / \mathrm{z}$. The temperatures of the Curved Desolvation Line (CDL) capillary and heat block were set at $200{ }^{\circ} \mathrm{C}$. The injected volume of the sample was $2 \mu \mathrm{L}$ and $5 \mu \mathrm{L}$, respectively.

\subsection{Chemicals}

The following chemicals were used to prepare the solutions and mobile phases: water for LC-MS, acetonitrile for LC-MS (both from LiChrosolv, Merck, Darmstadt, Germany), and formic acid for LC-MS (Sigma-Aldrich, Steinheim, Germany). Standard selected polyphenolic compounds were obtained from Sigma-Aldrich.

\subsection{Sampling and sample preparation}

The samples of nettle (Urtica dioica L.) were collected in March 2017 in the geographical area of Hruštín, after which they were dried and stored in a dry and dark place. Samples of bear's garlic (Allium ursinum L.) were collected in March 2017 in the geographical area of Bratislava, after which they were dried and stored in a dry and dark place. Prior to the analysis, the extracts of each sample were prepared as follows: approximately $0.5 \mathrm{~g}$ of each was weighed and $50 \mathrm{~mL}$ of water was poured onto them at $97{ }^{\circ} \mathrm{C}$. The extraction times were 5, 10 and 15 mins. The extracts were then filtered through filter paper and cooled to room temperature. After cooling, the samples were filtered through a syringe microfilter (PVDF with pore size $0.22 \mu \mathrm{m}$ ) and then analyzed using HPLCESI-MS/MS or stored in a refrigerator at $4{ }^{\circ} \mathrm{C}$ for a maximum of 24 hours.

\section{Results and Discussion}

The first part of the experimental work focused on the optimization of conditions for the chromatographic separation of phenolic compounds in selected extracts prepared

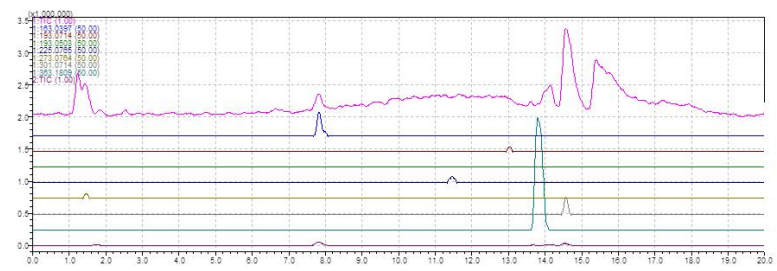

Figure 1: HPLC-ESI-MS analysis of the nettle extract (5 min extraction) with the addition of $10 \mathrm{mmol} / \mathrm{L}$ formic acid to the mobile phases. TIC (total ion current) in the positive mode - Top: TIC in the negative mode - Bottom and Middle: EIC (extracted ion chromatogram) records of identified phenolic compounds included.

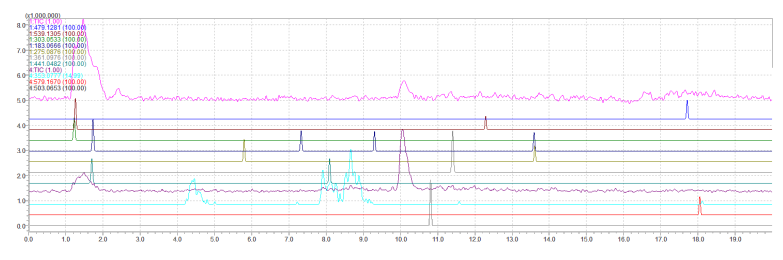

Figure 2: HPLC-ESI-MS analysis of the nettle extract (5 min extraction) with the addition of $0.1 \%$ formic acid to the mobile phases. TIC in the positive mode - Top: TIC in the negative mode - Bottom and Middle: EIC records of identified phenolic compounds included.

from different plant species. After HPLC separation, optimization with regard to the composition of the mobile phase in terms of the ionization of the analytes was performed. To confirm the effect with regard to the composition of the mobile phase on the resulting MS signal, a simple experiment was proposed. HPLC-ESI-MS/MS analysis of the bear's garlic and nettle extracts used mobile phases, which varied according to only the concentration of the added formic acid. Gradient elution utilized the following mobile phases with the addition of different concentrations of formic acid: $0.1 \%$ formic acid in water (A) $/ 0.1 \%$ formic acid in acetonitrile (B), and 10 $\mathrm{mmol} / \mathrm{L}$ formic acid in water $(\mathrm{A}) / 10 \mathrm{mmol} / \mathrm{L}$ formic acid in acetonitrile (B). For illustrative purposes, Figs. 1 and 2 show the results from the HPLC-ESI-MS analysis of the 5-minute- long extraction of nettles. After comparing these results with the results of measuring a 5-minutelong extraction of nettles with the addition of $0.1 \%(26.5$ $\mathrm{mmol} / \mathrm{L}$ ) formic acid to the mobile phases, it is clear that the use of a higher concentration of formic acid is more appropriate for the analysis of nettle extracts (promoting the protonation of molecules).

A similar procedure was used to select the appropriate composition of the mobile phases for HPLC-ESIMS analysis of the garlic extract. The results of the 15minute-long extraction of bear's garlic with the addition of $0.1 \%$ formic acid to the mobile phases can be seen in Fig. 3. The results of the 15-minute-long extraction of garlic with the addition of $10 \mathrm{mmol} / \mathrm{L}$ formic acid are recorded in Fig. 4 and suggest this is preferable for the 


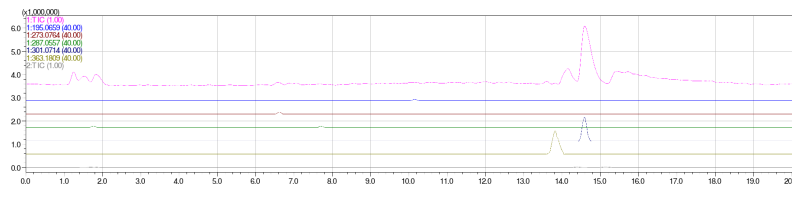

Figure 3: HPLC-ESI-MS analysis of the garlic extract (15 min extraction) with the addition of $0.1 \%$ formic acid to the mobile phases. TIC in the positive mode - Top: TIC in the negative mode - Bottom and Middle: EIC records of identified phenolic compounds included.

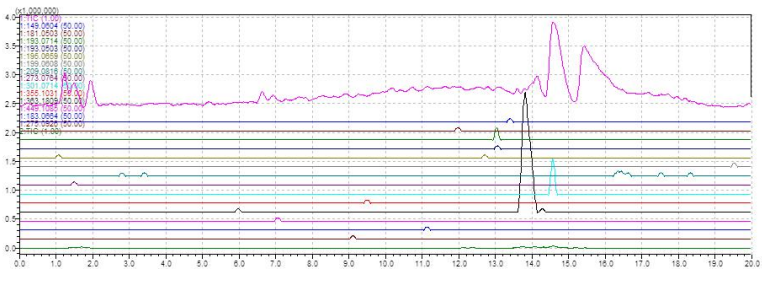

Figure 4: HPLC-ESI-MS analysis of the bear's garlic extract ( $15 \mathrm{~min}$ extraction) with the addition of $10 \mathrm{mmol} / \mathrm{L}$ formic acid to the mobile phases. TIC in the positive mode - Top: TIC in the negative mode - Bottom and Middle: EIC records of identified phenolic compounds included.

analysis of the garlic samples. The final conditions for chromatographic separation and mass spectrometric detection are described in detail in the experimental section.

On the basis of the data gathered from HPLC-ESIMS analyses, it is possible to obtain a better overview of the composition of individual extracts prepared from different plant species as well as information on the nature and structure of the phenolic compounds contained therein. The characterization and identification of individual polyphenolic compounds in plant extracts was performed by the analysis of the MS1-MS2 spectra that were recorded.

The MS1 and MS2 spectra of the coumaric acid in the sample of the nettle extract can be seen in Fig. 5. In the MS1 spectrum an ion with $m / z, 163.0471$ related to the coumarone $[\mathrm{M}-\mathrm{H}]^{-}$ion is observed. In the MS2 spectrum obtained by the fragmentation of coumaric acid, the ion with $\mathrm{m} / \mathrm{z}$ 119.0612, which was formed by cleaving the carboxyl group from the coumaric acid molecule, is visible. Another analyte found in the nettle sample was

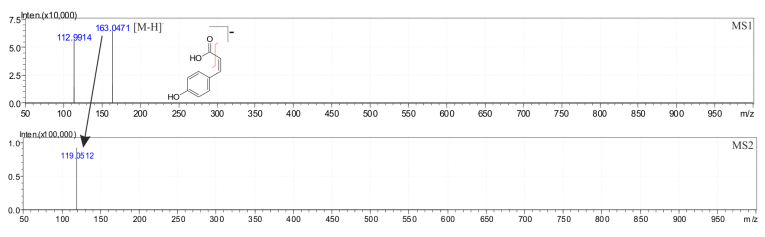

Figure 5: MS1 and MS2 spectra corresponding to coumaric acid obtained by HPLC-ESI-MS/MS analysis of the nettle extract (15 min extraction) in the negative ionization mode.

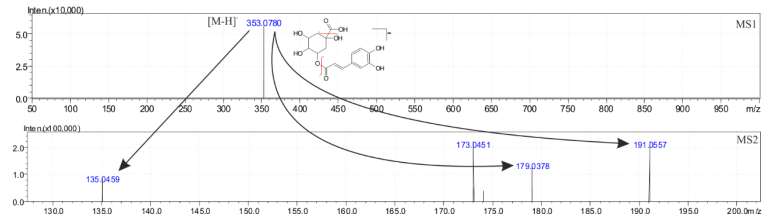

Figure 6: MS1 and MS2 spectra of the corresponding chlorogenic acid obtained by HPLC-ESI-MS/MS analysis of the nettle extract (15 min extraction) in the negative ionization mode.

chlorogenic acid, the presence of which was confirmed by the MS1 and MS2 spectra shown in Fig. 6. The MS1 spectrum is dominated by the ion with $\mathrm{m} / \mathrm{z} 353.0780$ corresponding to the $[\mathrm{M}-\mathrm{H}]^{-}$ion of chlorogenic acid. In the MS2 spectrum obtained by the fragmentation of the ion with $m / z$ 353.0780, the ion with $m / z$ 191.0557, which was obtained by cleaving $-\mathrm{C}_{9} \mathrm{O}_{3} \mathrm{H}_{7}$ from the chlorogenic acid molecule, is identified. In this spectrum another ion with $m / z$ 179.0378, which was formed by cleaving $-\mathrm{C}_{7} \mathrm{O}_{5} \mathrm{H}_{6}$ from the chlorogenic acid molecule, is observed. In the MS2 spectrum an ion with $m / z 173.0451$ is also seen, which corresponds to this cleavage. An ion with $\mathrm{m} / \mathrm{z}$ 135.0459 in MS2 seen in the chlorogenic acid spectrum was probably generated by cleaving the carboxyl group from the ion $m / z 179.0378$.

As in the case of the HPLC-ESI-HRMS analysis of nettle extracts, tandem mass spectrometry was used to identify polyphenolic substances in garlic extracts. As an illustration, the MS1 and MS2 chlorogenic acid spectra are presented in Fig. 7. In the MS1 spectrum the molecular ion $[\mathrm{M}-\mathrm{H}]^{-}$with $\mathrm{m} / \mathrm{z}$ 353.0844, which is associated with chlorogenic acid, in a sample of the garlic extract is seen. In the MS2 spectrum the ions with $\mathrm{m} / z$ 191.0496 and 179.0298, which were formed from the precursor ion $(\mathrm{m} / \mathrm{z}$ 353.0844) and belong to the illustrated chlorogenic acid fragments, are observed.

The identification of each polyphenolic compound was possible by recording the retention time as well as mass spectra of samples and authentic standards.

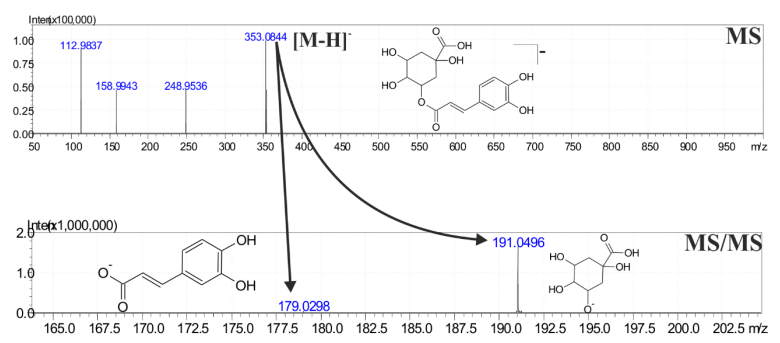

Figure 7: MS and MS/MS spectra corresponding to chloroformic acid obtained by HPLC-ESI-MS/MS analysis of the bear's garlic extract (10 min extraction) in the negative ionization mode. 


\section{Conclusion}

In our experimental work, the use of advanced mass spectrometry techniques in combination with highperformance liquid chromatography-mass spectrometry $\left(\mathrm{HPLC} \mathrm{MS}^{n}\right.$ ) for the analysis and identification of polyphenolic compounds in extracts prepared from different types of green foods was our focus. From the HPLC-MS ${ }^{n}$ data obtained by analyzing extracts from different types of green food, it was possible to obtain information about the composition of the analyzed extracts as well as information about the nature and structure of the polyphenolic compounds represented therein. Using the developed HPLC-ESI-IT-TOF-MS method, the presence of 13 antioxidants in the sample of nettle extracts and 16 antioxidants in the sample of garlic extracts was confirmed. Based on the results obtained, it can be stated that the developed HPLC-MSn method is a suitable tool for the characterization and identification of polyphenolic compounds in extracts prepared from green foods.

\section{Acknowledgement}

This research was supported by the grants VVCE-007007 and APVV-0583-11 of the Slovak Research and Development Agency (SRDA) and grant of Comenius University GUK/321/2017.

\section{REFERENCES}

[1] Gil, E. S.; Couto, R. O.: Flavonoid electrochemistry: a review on the electroanalytical applications, Revista Brasileira de Farmacognosia, 2013 23(3), 542-558 DOI: 10.1590/s0102-695x2013005000031

[2] Boros, B.; Jakabová, S.; Dörnyei, Á.; Horváth, G.; Pluhár, Z.; Kilár, F.; Felinger, A.: Determination of polyphenolic compounds by liquid chromatography-mass spectrometry in Thymus species, J. Chromatography A, 2010 1217(51), 7972-7980 DOI: 10.1016/j.chroma.2010.07.042

[3] Ginjom, I.; D’Arcy, B.; Caffin, N.; Gidley, M.: Phenolic compound profiles in selected Queensland red wines at all stages of the wine-making process, Food Chemistry, 2011 125(3), 823-834 DOI: 10.1016/j.foodchem.2010.08.062

[4] Atoui, A.; Mansouri, A.; Boskou, G.; Kefalas, P.: Tea and herbal infusions: Their antioxidant activity and phenolic profile, Food Chemistry, 2005 89(1), 27-36 DOI: 10.1016/j.foodchem.2004.01.075

[5] Tsao, R.: Chemistry and Biochemistry of Dietary Polyphenols, Nutrients, 2010 2(12), 1231-1246 DOI: 10.3390/nu2121231

[6] Orčić, D.; Francišković, M.; Bekvalac, K.; Svirčev, E.; Beara, I.; Lesjak, M.; Mimica-Dukić, N.: Quantitative determination of plant phenolics in Urtica dioica extracts by high-performance liquid chromatography coupled with tandem mass spectrometric detection, Food Chemistry, 2014 143, 48-53 DOI: 10.1016/j.foodchem.2013.07.097
[7] Baskaran, R.; Pullencheri, D.; Somasundaram, R.: Characterization of free, esterified and bound phenolics in custard apple (Annona squamosa L) fruit pulp by UPLC-ESI-MS/MS, Food Research International, 2016 82, 121-127 DOI: 10.1016/j.foodres.2016.02.001

[8] Comandini, P.; Lerma-García, M. J.; Simó-Alfonso, E. F.; Toschi, T. G.: Tannin analysis of chestnut bark samples (Castanea sativa Mill.) by HPLCDAD-MS, Food Chemistry, 2014 157, 290-295 DOI: 10.1016/j.foodchem.2014.02.003

[9] Ma, Y.; Kosińska-Cagnazzo, A.; Kerr, W. L.; Amarowicz, R.; Swanson, R. B.; Pegg, R. B.: Separation and characterization of phenolic compounds from dry-blanched peanut skins by liquid chromatography-electrospray ionization mass spectrometry, J. Chromatography A, 2014 1356, 64-81 DOI: 10.1016/j.chroma.2014.06.027

[10] Jiang, H.; Timmermann, B. N.; Gang, D. R.: Characterization and identification of diarylheptanoids in ginger (Zingiber officinale Rosc.) using highperformance liquid chromatography/electrospray ionization mass spectrometry, Rapid Communications in Mass Spectrometry, 2007 21(4), 509-518 DOI: $10.1002 / \mathrm{rcm} .2858$

[11] Lucini, L.; Pellizzoni, M.; Baffi, C.; Molinari, G. P.: Rapid determination of lycopene and $\beta$-carotene in tomato by liquid chromatography/electrospray tandem mass spectrometry, Journal of the Science of Food and Agriculture, 2011 92(6), 1297-1303 DOI: $10.1002 /$ jsfa.4698

[12] Dachtler, M.; Glaser, T.; Kohler, K.; Albert, K.: Combined HPLC-MS and HPLC-NMR On-Line Coupling for the Separation and Determination of Lutein and Zeaxanthin Stereoisomers in Spinach and in Retina, Anal. Chem., 2001 73(3), 667-674 DOI: $10.1021 / \mathrm{ac} 000635 \mathrm{~g}$

[13] Petry, F. C.; Mercadante, A. Z.: Composition by LC-MS/MS of New Carotenoid Esters in Mango and Citrus, Journal of Agricultural and Food Chemistry, 2016 64(43), 8207-8224 DOI: 10.1021/acs.jafc.6b03226

[14] Farag, M. A.; Weigend, M.; Luebert, F.; Brokamp, G.; Wessjohann, L. A.: Phytochemical, phylogenetic, and anti-inflammatory evaluation of $43 \mathrm{Ur}$ tica accessions (stinging nettle) based on UPLCQ-TOF-MS metabolomic profiles, Phytochemistry, 2013 96, 170-183 DOI: 10.1016/j.phytochem.2013.09.016

[15] Vlase, L.; Pârvu, M.; Parvu, A. E.; Toiu, A.: Phytochemical analysis of Allium fistulosum L. and A. Ursinum L, Digest Journal of Nanomaterials and Biostructures, 2012 8, 457-467 